\title{
CORRELATIONS BETWEEN SUBJECTIVE AND OBJECTIVE FEATURES OF NOCTURNAL SLEEP AND EXCESSIVE DIURNAL SLEEPINESS IN PATIENTS WITH NARCOLEPSY
}

\author{
Ulises Jiménez-Correa ${ }^{1,2}$, Reyes Haro', Rosa Obdulia González , Javier Velázquez-Moctezuma²
}

\begin{abstract}
Objective: To determine the correlations between excessive daytime sleepiness (EDS), assessed by the Epworth sleepiness scale (ESS), and the multiple sleep latency test (MSLT) and nocturnal sleep architecture features, clinical symptoms of narcolepsy (CSN) and subjective sleep quality (SSQ) in patients with narcolepsy. Method: Twenty three untreated patients were studied and compared with a matched control group. Diagnosis of narcolepsy was carried out employing a clinical interview, a polysomnographic (PSG) record, and an MSLT. Results: Subjective number of awakenings was the SSQ indicator that best correlated with EDS (ESS and MSLT). Regarding clinical features, diurnal tiredness and sleep paralysis correlated with ESS values. Increase in ESS was related with decrease in total sleep time, SWS, and sleep onset latency. On the other hand, increase in MSLT was related with decrease in SWS. Conclusion: These data suggest that EDS in patients with narcolepsy could be impaired by disturbed nocturnal sleep.
\end{abstract}

KEY WORDS: narcolepsy, clinical symptoms, subjective sleep quality, sleep architecture, Epworth sleepiness scale, multiple sleep latency test, excessive daytime sleepiness.

\section{Correlação entre as caracteristicas objetivas e subjetivas do sono noturno e a hipersonolência diurna em pacientes narcolepticos}

Resumo - Objetivo: Determinar as correlações entre hipersonolência, avaliada pela escala de sonolência Epworth (ESE) e o teste múltiplo de latência do sono (TMLS) com a arquitetura do sono (AS), sintomas e qualidade subjetiva do sono em pacientes narcolepticos. Método: Comparou-se um grupo de vinte e tres pacientes narcolepticos sem tratamento com grupo controle. O diagnóstico de narcolepsia foi realizado por uma entrevista clinica, polissonografia e o TMLS. Resultados: O número subjetivo de despertares foi o indicador com maior relação com a hipersonolência, o cansaço diurno e a paralisia do sono também foi correlacionados com a ESE.O aumento do índice na ESE foi correlacionado com uma diminuição do tempo total do sono, no sono de ondas lentas (SOL) e com a latência para o início do sono. O incremento na TMLS foi relacionado com diminuição do SOL. Conclusão: Os dados sugerem que a hipersonolência diurna em pacientes portadores de narcolepsia pode se correlacionar com as alterações da arquitetura do sono noturno.

PALAVRAS-CHAVE: sintoma clínico de narcolepsia, qualidade subjetiva do sono, teste múltiplo de latência do sono, hipersonolência.

Narcolepsy is a sleep disorder first described as a condition characterized by excessive daytime sleepiness (EDS), sleep attacks, and episodes of muscle weakness triggered by strong emotions. More recently, narcolepsy has been characterized by the presence of EDS, cataplexic episodes, and rapid eye movement (REM) sleep-related abnormalities'. The most recent International Classification of Sleep Disorders (ICSD) describes several subtypes

\footnotetext{
${ }^{1}$ Clínica de Trastornos de Sueño, Facultad de Medicina, Universidad Nacional Autónoma de México, Distrito Federal, México; ${ }^{2}$ Clínica de Sueño, División de Ciencias Biológicas y de la Salud, Universidad Autónoma Metropolitana, Unidad Iztapalapa, Distrito Federal, México; ${ }^{3}$ Departamento de Matemáticas, Universidad Autónoma Metropolitana, Unidad Iztapalapa, Distrito Federal, México.

This study was partly supported by CONACyT-México grant \# 119549 (to UJC). The study is part of the Doctoral Degree in Experimental Biology of UJC at the Universidad Autónoma Metropolitana Unidad Iztapalapa.

Received 13 February 2009, received in final form 10 July 2009. Accepted 20 July 2009.

Dr. Ulises Jiménez Correa - Clínica de Trastornos de Sueño / Unidad de Medicina Experimental (U.N.A.M.) / Hospital General de México - Dr. Balmis 148, Colonia Doctores, Delegación Cuauhtémoc - Distrito Federal, México - C.P.06726. E-mail: ulisesjc@yahoo.com
} 
of narcolepsy according to their clinical features, and the possible presence or absence of cataplexy has been recognized. Nevertheless, EDS remains a common element in all narcolepsy subtypes ${ }^{2}$. EDS is usually the most disabling symptom and the first to occur. It is characterized by repeated episodes of naps or lapses of sleep during daytime ${ }^{2}$. In contrast to physiologic sleepiness (e.g., after sleep deprivation), EDS in narcolepsy is frequently constant, severe, and only transiently and partially improved with sleep. Naps in patients with narcolepsy are usually of short duration, typically lasting between 10 and $20 \mathrm{~min}$ and $<1 \mathrm{~h}$. Patients wake up feeling refreshed, but within $2-3 \mathrm{~h}$ they begin to feel sleepy again ${ }^{3}$. Moreover, untreated individuals with narcolepsy cannot stay awake for 16 consecutive hours, and events that normally occurs during REM sleep occurs during the waking period ${ }^{4}$.

The sleep architecture (SA) of subjects with narcolepsy has been characterized by the following: (1) REM episodes at sleep onset; (2) long periods of wakefulness after sleep onset and, correspondingly, poor sleep efficiency, and (3) normal amounts of REM sleep ${ }^{5}$. Disturbed sleep is a significant feature in narcolepsy ${ }^{6}$. Nocturnal sleep disruption can be found in approximately $50 \%$ of patients with narcolepsy; most typically, the sleep maintenance insomnia symptom, an increase in the amount of sleep stage 1, and awakenings are observed. It is frequently a very disabling symptom that may exacerbate all other symptoms ${ }^{2,7}$. Once sleep is initiated, a high number of sleep-stage transitions, short bouts of wakefulness, and/ or sustained wake periods occur within the sleep period ${ }^{8}$. These changes occur mainly in the second non-rapid eye movement (NREM) sleep episode leading to an impaired build-up of slow wave activity, suggesting an insufficient NREM period intensity in narcolepsy'. There is no consensus concerning the relationship between EDS and SA in narcolepsy. Chervin, Kraemer, and Guilleminault ${ }^{10}$ concluded that mean sleep latency in the multiple sleep latency test (MSLT) in a clinical population does not correlate with a number of variables expected to influence sleepiness. Broughton et al." did not find significant correlation between EDS and nocturnal sleep. They concluded that diurnal sleep (involuntary naps) in narcolepsy is based upon a different mechanism, perhaps a diurnal "sub-vigilance syndrome," or an impaired arousal mechanism. However, Browman et al. ${ }^{12}$ found that measures of nocturnal REM sleep for subjects with narcolepsy correlated with sleep latency in the MSLT. In particular, REM latency at night was highly predictive of the magnitude of hypersomnia for patients with narcolepsy. Harsh et al. ${ }^{6}$ reported that abnormal sleep structure and sleep fragmentation are related with the EDS of patients with narcolepsy.

In this study, we analyzed the correlation between clinical symptoms of narcolepsy (CSN), subjective sleep quality (SSQ), and SA and EDS severity utilizing ESS and MSLT instruments in untreated patients with narcolepsy without co-morbid sleep disorders.

\section{METHOD}

The study was performed at the Sleep Disorders Clinic of the School of Medicine at the National Autonomous University of Mexico (UNAM). This was a retrospective study in which we included 23 untreated patients with narcolepsy, including four males and 19 females (age range, 18-57 years; mean, 31.95 years; standard deviation [SD], \pm 10.07 ); 19 had cataplexy. In addition, 23 healthy subjects were used as a matched control group.

The aim was to determine the relationship between SSQ, CSN, and SA and EDS (ESS/MSLT). All patients met criteria for diagnosis of narcolepsy as described in the International Classification of Sleep Disorders ${ }^{13}$ and responded to the Epworth Sleep scale (ESS) instrument ${ }^{14}$. Additionally, nocturnal polysomnographic (PSG) records ${ }^{15,16}$ and the multiple sleep latency test $(M S L T)^{17,18}$ were performed on each patient.

Patients with narcolepsy exhibiting PSG evidence of a concurrent EDS-inducing disorder such as primary snoring, sleep breathing disorders, or periodic leg movements during sleep were not included in the study (six patients were excluded from statistical analysis). In addition, patients with any other medical condition that may cause nocturnal sleep disruption, EDS, and those with a smoking, alcohol, or psychiatric medication history were also excluded.

PSG was performed from 23:00 p.m. to 7:30 a.m. (for \pm 30 min) following standard procedures and including EEG recording ( $\mathrm{C} 3-\mathrm{A} 2, \mathrm{C} 4-\mathrm{A} 1, \mathrm{O} 1-\mathrm{A} 2, \mathrm{O} 2-\mathrm{A} 1)$, Electro-oculogram (EOG), chin Electromyogram (EMG), nasal and oral air flow (Grass thermocouple 1401G\&1421), thoracic and abdominal respiratory effort (Grass Piezo crystal film F-RCTA \& F-RCTP), snoring (Grass sensor 1696), arterial pulse/oxygen (Grass pulse oximeter sensor $8000 \mathrm{AA}$ ), and anterior tibial EMG. MSLT was performed the subsequent morning with simultaneous recording of EEG, EOG, and EMG in four sessions at 9:30 a.m., 11:30 a.m., 13:30 p.m., and 15:30 p.m. (only four nap opportunities due to the presence of REM sleep in at least two sessions) ${ }^{18}$.

PSG records and the MSLT were performed with two biologic polygraphic recording systems, utilizing Sleep Scan 3.1 software (1993, Chicago IL, USA) and with a Cadwell system with Easy 2.0 software (2003, Kellogg, St. Kennewick, WA, USA); PSG and MSLT were scored visually by a trained sleep disorders technician according to standard criteria.

Student $t$ test for independent groups were performed to compare SA between narcolepsy and control groups. Spearman correlation tests were conducted to determine the relationship between SSQ and the total score of ESS or MSLT.

To determine the relationship between CSN (negative/positive) and ESS or MSLT (negative/positive), Pearson chi square test were also performed. An ESS score $>10$ and an MSLT determination of $<8$ min were considered abnormal or positive ${ }^{2,19}$. Fi- 
nally, the relationship between ESS or MSLT and SA were calculated with Spearman correlation tests. Statistical analysis was carried out with SPSS v. 10.0 software (Chicago, IL, USA). Protocol was approved by the hospital ethics committee and all participants signed an informed consent form.

\section{RESULTS}

Patients with narcolepsy showed remarkably higher ESS values (mean, 19.04 \pm SD 3.95). Moreover, MSLT results demonstrated expected latency shortage, given the diagnosis of narcolepsy (sleep onset latency, $5.60 \mathrm{~min} \pm \mathrm{SD}$ 3.43; REM sleep latency, $6.02 \mathrm{~min} \pm$ SD 2.91). According to previous studies ${ }^{14}$, we found a significant negative correlation between ESS and sleep latency in MSLT (rho, -0.410; $\mathrm{p}<0.041$ ); however, the correlation between ESS and REM latency in MSLT was not significant (rho, -0.343 ; $\mathrm{p}<0.075$ ).

Table 1 summarizes SA-associated data. Compared with control subjects, patients with narcolepsy exhibit- ed a significant increase in light sleep percentage (sleep stages 1 and 2), number of arousals and awakenings, and ESS, as well as shortening in sleep onset latency and REM sleep latency. A significant decrease was observed in the percentage of Slow-wave sleep (SWS) and REM sleep. We found no significant differences in total sleep time, wakefulness percentage, and sleep efficiency index.

Regarding subjective sleep quality, we found a positive correlation between subjective number of awakenings and total score in ESS (rho, 0.637; $\mathrm{p}<0.002$ ), as well as a negative correlation between subjective number of awakenings and MSLT (rho, $-0.391, \mathrm{p}<0.049$ ). We found no significant correlation between subjective sleep latency and subjective sleep time and ESS or MSLT (Table 2). With respect to clinical symptoms of narcolepsy, we found a positive correlation between ESS with diurnal tiredness (Pearson $\chi^{2}=$ $12.48, \mathrm{p}<0.000$ ) and with sleep paralysis (Pearson $\chi^{2}, 4.455$; $\mathrm{p}<0.035$ ), but we found no significant correlation between

Table 1. Sleep architecture comparison between control subjects and patients with narcolepsy.

\begin{tabular}{|c|c|c|c|}
\hline Sleep architecture & $\begin{array}{c}\text { Control subjects } \\
\text { Mean } \pm S D\end{array}$ & $\begin{array}{l}\text { Patients with narcoplexy } \\
\text { Mean } \pm S D\end{array}$ & $+p$ values \\
\hline Total sleep time (min) & $440.6 \pm 18.89$ & $429.02 \pm 29.5$ & $<0.120$ NS \\
\hline Total sleep time (h) & $7.34 \pm 0.31$ & $7.15 \pm 0.49$ & $<0.120$ NS \\
\hline Wakefulness (\%) & $8.64 \pm 3.10$ & $11.44 \pm 7.24$ & $<0.098$ NS \\
\hline Sleep stage $1(\%)$ & $10.57 \pm 1.71$ & $16.60 \pm 6.07$ & $<0.000^{*}$ \\
\hline Sleep stage $2(\%)$ & $52.09 \pm 3.85$ & $58.36 \pm 7.58$ & $<0.001 *$ \\
\hline Light sleep (\%) & $62.66 \pm 3.59$ & $74.97 \pm 9.44$ & $<0.000^{*}$ \\
\hline Sleep stage $3(\%)$ & $9.84 \pm 2.29$ & $4.8 \pm 3.82$ & $<0.000^{*}$ \\
\hline Sleep stage $4(\%)$ & $9.02 \pm 1.83$ & $4.03 \pm 4.61$ & $<0.000^{*}$ \\
\hline Slow wave sleep (\%) & $18.86 \pm 3.43$ & $8.36 \pm 6.16$ & $<0.000^{*}$ \\
\hline REM sleep (\%) & $18.65 \pm 2.46$ & $16.00 \pm 4.78$ & $<0.025^{\star}$ \\
\hline Sleep efficiency index & $91.34 \pm 3.10$ & $88.55 \pm 7.30$ & $<0.102$ NS \\
\hline Number of arousals & $29.13 \pm 8.47$ & $78.38 \pm 44.46$ & $<0.000^{*}$ \\
\hline Number of awakenings ( $<3 \mathrm{~min}$ ) & $3.77 \pm 2.18$ & $35.15 \pm 15.54$ & $<0.000^{*}$ \\
\hline Sleep onset latency (min) & $9.89 \pm 2.79$ & $6.78 \pm 6.97$ & $<0.050^{*}$ \\
\hline Sleep stage 2 latency (min) & $11.00 \pm 3.67$ & $6.64 \pm 6.86$ & $<0.011^{*}$ \\
\hline REM sleep latency (min) & $95.67 \pm 12.88$ & $52.04 \pm 40.36$ & $<0.000 *$ \\
\hline Epworth Sleepiness Scale & $6.22 \pm 3.14$ & $19.04 \pm 3.95$ & $<0.000^{*}$ \\
\hline
\end{tabular}

SD: standard deviation; +: Student $t$ test ; ${ }^{*} \mathrm{p}<0.05$; NS: not significant; REM: rapid eye movement.

Table 2. Correlations between EDS (ESS/MSLT) and SSQ in narcolepsy.

\begin{tabular}{lcccc}
\hline SSQ in patients with narcolepsy & ESS rho & $\mathrm{p}<$ & MSLT rho & $\mathrm{p}<$ \\
\hline Subjective sleep latency & -0.166 & $0.236 \mathrm{NS}$ & 0.119 & $0.136 \mathrm{NS}$ \\
Subjective sleep time & 0.093 & $0.352 \mathrm{NS}$ & -0.277 & $0.303 \mathrm{NS}$ \\
Subjective number of awakenings & 0.637 & 0.002 & -0.391 & 0.049 \\
\hline
\end{tabular}

EDS: excessive daytime sleepiness; SSQ: subjective sleep quality; rho: Spearman correlation; ESS: Epworth sleepiness scale; MSLT: multiple sleep latency test. * $\mathrm{p}<0.05$; NS: not significant. 
Table 3. Correlations between CSN and EDS (ESS/MSLT).

\begin{tabular}{lcccc}
\hline Clinical symptoms of narcolepsy & ESS $\chi^{2}$ & $\mathrm{p}<$ & MSLT $\chi^{2}$ & $\mathrm{p}<$ \\
\hline Diurnal tiredness (positive/negative) & 0.375 & 0.047 & 0.037 & 0.437 NS \\
Cataplexy (positive/negative) & 0.072 & $0.392 \mathrm{NS}$ & -0.009 & 0.484 NS \\
Sleep paralysis (positive/negative) & 0.539 & 0.016 & -0.100 & 0.329 NS \\
Hypnagogic hallucinations (positive/negative) & 0.303 & 0.136 NS & 0.009 & 0.485 NS \\
\hline$\chi^{2}$ : Pearson chi square; CSN: clinical symptoms of narcolepsy; EDS: excessive daytime sleepiness; ESS: Epworth sleepiness scale; MSLT: multiple \\
sleep latency test; ${ }^{p}<0.05$; NS: not significant.
\end{tabular}

Table 4. Correlation between ESS/MSLT with sleep architecture in patients with narcolepsy.

\begin{tabular}{|c|c|c|c|c|}
\hline Sleep architecture & ESS rho & $\mathrm{p}$ & MSLT rho & $\mathrm{p}$ \\
\hline Total sleep time (min) & -0.562 & $0.003^{*}$ & 0.169 & 0.245 N.S \\
\hline Sleep efficiency & -0.500 & $0.008^{*}$ & 0.105 & $0.334 \mathrm{NS}$ \\
\hline Wakefulness (\%) & 0.542 & $0.004^{*}$ & -0.100 & $0.342 \mathrm{NS}$ \\
\hline Sleep stage $1(\%)$ & 0.305 & $0.078 \mathrm{NS}$ & 0.194 & $0.213 \mathrm{NS}$ \\
\hline Sleep stage 1 (min) & 0.222 & 0.154 NS & 0.300 & $0.106 \mathrm{NS}$ \\
\hline Sleep stage $2(\%)$ & -0.023 & $0.459 \mathrm{NS}$ & 0.265 & 0.137 NS \\
\hline Sleep stage 2 (min) & -0.337 & $0.058 \mathrm{NS}$ & 0.520 & $0.011^{*}$ \\
\hline Light sleep (min) & -0.193 & 0.189 N.S & 0.508 & $0.013^{*}$ \\
\hline Light sleep (\%) & 0.182 & $0.203 \mathrm{NS}$ & 0.349 & $0.072 \mathrm{NS}$ \\
\hline Sleep stage 3 (min) & -0.066 & 0.382 NS & -0.371 & $0.059 \mathrm{NS}$ \\
\hline Sleep stage 3 (\%) & -0.064 & $0.386 \mathrm{NS}$ & -0.439 & $0.030 *$ \\
\hline Sleep stage 4 (\%) & -0.401 & $0.029 *$ & -0.234 & 0.167 NS \\
\hline Sleep stage 4 (min) & -0.406 & $0.027^{*}$ & -0.243 & 0.158 NS \\
\hline Slow wave sleep (\%) & -0.183 & $0.201 \mathrm{NS}$ & -0.431 & $0.033^{*}$ \\
\hline Slow wave sleep (min) & -0.347 & $0.050^{*}$ & -0.314 & $0.095 \mathrm{NS}$ \\
\hline REM sleep (\%) & 0.082 & 0.355 N.S & -0.240 & 0.161 N.S \\
\hline REM sleep (min) & -0.037 & 0.433 N.S & -0.178 & 0.233 N.S \\
\hline Sleep onset latency (min) & -0.428 & $0.021^{*}$ & 0.288 & 0.116 NS \\
\hline REM sleep latency & -0.251 & $0.130 \mathrm{NS}$ & 0.101 & $0.340 \mathrm{NS}$ \\
\hline Number of nocturnal awakenings ( $<3 \mathrm{~min}$ ) & 0.513 & $0.012^{*}$ & -0.012 & $0.484 \mathrm{NS}$ \\
\hline Number of arousals & 0.091 & $0.348 \mathrm{NS}$ & 0.229 & $0.188 \mathrm{NS}$ \\
\hline
\end{tabular}

rho: Spearman correlation analysis; ESS: Epworth sleepiness scale; MSLT: multiple sleep latency test. *p<0.05; REM: rapid eye movement; NS: not significant.

ESS and cataplexy or hypnagogic hallucinations. In addition, no significant correlation was found between MSLT and diurnal tiredness, cataplexy, sleep paralysis, or hypnagogic hallucinations (Table 3).

Table 4 presents the correlation between SA and EDS (ESS and MSLT). Wakefulness percentage and number of nocturnal awakenings showed a significant positive correlation with ESS, while total sleep time (TST), sleep efficiency (SE), percentage of sleep stage 4, SWS, and sleep onset latency exhibited a negative correlation with ESS. Percentage of light sleep, REM sleep, REM sleep latency and number of arousals showed no significantly correlation with ESS.
Regarding objective EDS, we found that sleep stage 2 ( $\mathrm{min}$ ) and light sleep ( $\mathrm{min}$ ) demonstrated a significant positive correlation with MSLT, whereas the percentage of sleep stage 3 and SWS were negatively correlated with MSLT. We found no significant correlation between percentage of sleep stages (1, 2, 4, and REM), as well as latencies to sleep onset and REM sleep with MSLT.

\section{DISCUSSION}

The impact of nocturnal sleep on EDS level in narcolepsy has been a matter of controversy. The present results support previously reported findings concerning a 
clear disturbance of the nocturnal sleep pattern in patients with narcolepsy ${ }^{5,711}$. It is possible that the increased number of arousals and awakenings comprised the main causes of changes in light sleep, slow wave sleep, and REM sleep in narcolepsy, also including sleep onset latency and REM sleep latency. There is solid evidence supporting the hypothesis that the increase in nocturnal SWS is important in EDS control in narcolepsy. For instance, nightly administration of sodium oxybate to patients with narcolepsy resulted in three major effects as follows: (1) initial induction and prolongation of REM sleep followed by subsequent reduction of this sleep state; (2) increase in SWS, and (3) improvement in daytime alertness despite the lack of a sodium-oxybate effect on total nocturnal sleep time. These results suggest that the observed improvement in narcoleptic symptoms, mainly EDS, is correlated with SA normalization ${ }^{20}$. If in narcolepsy SA resembles a sleep deprivation pattern and if sleep homeostasis is conserved, EDS could be, at least in part, a consequence of a chronic sleep deprivation in narcolepsy.

Although there is wide consensus with respect to important SA disturbances in narcolepsy; there is a lack of scientific interest concerning SSQ in this sleep disorder. According to our data, subjective number of awakenings was best correlated SSQ parameter with EDS (subjective and objective). These data suggest that SSQ could be an essential issue in clinical evaluation of narcolepsy. To our knowledge, the present results are the first in which the relationship between SSQ and EDS in narcolepsy has been studied.

According to CSN, ESS scores showed significant correlation with diurnal tiredness and sleep paralysis. However, we found no significant correlation between CSN and MSLT. It is possible that subjective awakenings and sleep paralysis are symptoms that present together, and they could disrupt sleep continuity; thus, they may be potential worsening factors of diurnal tiredness and mainly subjective EDS. Further research is required to clarify this particular subject.

Concerning the relation between SA and EDS, our results are similar to those in previous reports ${ }^{6}$, indicating that EDS severity is related with nocturnal sleep-disturbance severity in patients with narcolepsy. We found moderate correlations suggesting that increase of subjective sleepiness is related with an expected rise in nocturnal wake time and number of awakenings, and a decrease in total sleep time, sleep efficiency, and SWS, as well as in sleep onset latency. Also, we found that an increase in MSLT was related with an increase in sleep stage 2, light sleep and a decrease in SWS. This infers that ESS/MSLT could be a good indirect indicator of the degree of SA disturbance in narcolepsy. Perhaps an increase in nocturnal sleep quality (subjective and objective) decreases EDS.

Slow-wave activity has been studied in narcolepsy mainly to test the presence (or absence) of homeostatic regulation. For instance, an increase in SWS in patients with narcolepsy after sleep-deprivation periods (between 16 and $24 \mathrm{~h}$ ) supports the homeostatic regulation theory of NREM sleep intensity ${ }^{5}$. Volk et al. ${ }^{21}$ reported an increase in nocturnal SWS after daytime sleep deprivation in patients with narcolepsy and concluded that homeostatic regulation of sleep also operates in patients with narcolepsy. Coincidently, an increase in SWS was significantly correlated with a decrease in ESS. This might indicate that a decrease in SWS exerts a greater impact on subjective EDS and that, according to previous research, homeostatic regulation in narcolepsy is present.

We present herein objective and subjective evidence to support the hypothesis that EDS severity is related with nocturnal sleep disturbance. It may be possible that the sleep-architecture alteration level is a narcolepsy severity indicator, and that therefore, it is possible that improvement of nocturnal sleep will ameliorate EDS in patients with narcolepsy This possibility deserves further study to obtain a better understanding of narcolepsy.

\section{Limitations}

To strengthen statistical analysis, it is important to increase the number of subjects. However, due to the low prevalence of narcolepsy and the exclusion of patients with narcolepsy with snoring, sleep apnea, periodic limb movements, or pharmacological treatment, this will be difficult. In another regard, we have no data on human leukocyte antigen (HLA) typing of our narcolepsy sample. Although HLA (DQB1*0602 and DR2 or DRB1*1501 subtypes) is not diagnostic for narcolepsy (ICSD-II, 2005) it could be important to determine whether there is any possible relationship between EDS severity (ESS/MSLT) and HLA subtype in narcolepsy.

In conclusion, sleep architecture in narcolepsy is characterized by an increase in light sleep, number of arousals, and awakenings, and a decrease in SWS, REM sleep, sleep latency, and mainly REM sleep latency. The subjective number of awakenings was the SSQ indicator that best correlated with EDS (subjective and objective). Regarding CSN, positive diurnal tiredness and sleep paralysis were correlated with positive ESS, but any symptoms of narcolepsy were correlated with MSLT. An increase in ESS was correlated with a diminution in total sleep time, sleep efficiency, SWS, and sleep onset latency, and an increase in nocturnal wakefulness. In addition, an increase in MSLT correlated with a decrease in SWS and an increase in light sleep.

ACKNOWLEDGMENTS - The authors would like to thank Ms. Margaret Brunner, Ms. Irma Hernandez-Berber and Guadalupe Terán for their support on the English and Portuguese languages review. 


\section{REFERENCES}

1. Nishino S, Riehl J, Hong J, Kwan M, Reid M, Mignot E. Is narcolepsy a REM sleep disorder? Analysis of sleep abnormalities in narcoleptic Dobermans. Neurosci Res 2000;38:437-446.

2. American Academy of Sleep Medicine. International classification of sleep disorders: diagnostic and coding manual. $2^{\text {nd }} \mathrm{Ed}$. Westchester, IL, USA: American Academy of Sleep Medicine; 2005.

3. Thorpy M. Current concepts in etiology, diagnosis and treatment of narcolepsy. Sleep Med 2001;2:5-17.

4. Zeitzer JM, Nishino S, Mignot E. The neurobiology of hypocretins (orexins), narcolepsy and related therapeutic interventions. Trends Pharmacol Sci 2006;27:368-374.

5. Tafti M, Villemin E, Carlander B, Besset A, Billiard M. Sleep in human narcolepsy revisited with special reference to prior wakefulness duration. Sleep 1992;15:344-351.

6. Harsh J, Peszka J, Hartwig G, Mitler M. Night-time sleep and daytime sleepiness in narcolepsy. J Sleep Res 2000;9:309-316.

7. Guilleminault C, Fromherz S. Narcolepsy: diagnosis and management. In: Kryger M, Dement W, Roth T (Eds). Principles and practice of sleep medicine. Philadelphia, PA, USA: Elsevier-Saunders; 2005:780-790.

8. Broughton R, Krupa S, Boucher B, et al. Impaired circadian waking arousal in narcolepsy-cataplexy. Sleep Res on Line 1998;1:159-165.

9. Khatami R, Landlot H, Achermann P, et al. Insufficient non-Rem sleep intensity in narcolepsy-cataplexy. Sleep 2007;30:980-989.

10. Chervin RD, Kraemer HC, Guilleminault C. Correlates of sleep latency on the multiple sleep latency test in a clinical population. Electroencephalogr Clin Neurophysiol 1995;95:147-153.

11. Broughton R, Dunham W, Weisskopf M, Rivers M. Night sleep does not predict day sleep in narcolepsy. Electroencephalogr Clin Neurophysiol 1994;91:67-70.

12. Browman CP, Gujavarty KS, Yolles SF, Mitler MM. Forty-eight-hour polysomnographic evaluation of narcolepsy. Sleep 1986;9:183-188.

13. American Sleep Disorders Association. The international classification of sleep disorders: diagnostic and coding manual. Rochester, MN: American Sleep Disorders Association, 1990.

14. Johns MW. A new method for measuring daytime sleepiness: the Epworth sleepiness scale. Sleep 1991;14:540-545.

15. Chesson AL, and ASDA Standards of Practice Committee. Practice parameters for the indications for polysomnography and related procedures. Sleep 1997;20:406-422.

16. Rechtschaffen A, Kales A (Eds). A manual of standardized terminology, techniques and scoring system for sleep stages of human subjects. Washington, D.C., USA: US Government Printing Office;1968.

17. Carskadon MA, Dement WC, Mitler MM, Roth T, Wesbrook PR, Keenan S. Guidelines for the multiple sleep latency test (MSLT): a standard measure of sleepiness. Sleep 1986;9:519-524.

18. Littner MR, Kushida C, Wise M, et al. Practice parameters for clinical use of the multiple sleep latency test and the maintenance of wakefulness test. Sleep 2005;28:113-121.

19. Johns MW, Hocking B. Daytime sleepiness and sleep habits of Australian workers. Sleep 1997;20:844-849.

20. Mamelak M, Black J, Montplaisir J, Ristanovic R. A pilot study on effects of sodium oxybate on sleep architecture and daytime alertness in narcolepsy. Sleep 2004;27:1327-1334.

21. Volk S, Schulz H, Yassouridis A, Wilde-Frenz J, Simon O. The influence of two behavioral regimens on the distribution of sleep and wakefulness in narcoleptic patients. Sleep 1990;13:136-142. 